\title{
Habit and Habitat in the Galatheidea: a study in adaptation.
}

\author{
By
}

K. Zimmermann, B.Sc., University College of Wales, Aberystwyth.

With Figure 1 and Plates 1-4 in the Text.

THE heterogeneous assembly of Decapod Crustacean types classed as "Anomura" is well known to present a wide range of variation in structural features ; in fact, the most apparent bond of union between its highly dissimilar sub-groups consists in the still greater disparity which exists between these and members of either "Macrura" or "Brachyura" proper. The Anomura may best be compared with that other heterogeneous group, the Amphibia : each, apparently of aquatic ancestry, has suffered in the unequal contest with a highly specialized offset from the parent-stock (Brachyura-Reptilia); the survivors of both the ill-fated groups, Anomura and Amphibia, are few in number, varied in type, and probably not closely related among themselves.

Among the Anomura, the sub-group Galatheidea present a fairly connected natural assemblage of types. Study of this sub-group reveals the presence of two distinct and widely divergent lines of specializationon the one hand, for life on shore (near or above low-tide mark), and, on the other, for life in deeper waters. Thus the group comprises, together with more or less intermediate forms, three well-marked types :

\section{A. THE Galathea squamifera TYPE.}

The characteristic species frequents the fairly open seas which surround our coasts, and is rarely found near low-tide mark except for a short time in spring; the form of body is almost Macrurous, and the abdomen, though usually flexed, is relatively large, and of no little importance in swimming.

\section{B. The Porcellana platycheles TYPE.}

The characteristic species lives well up in the muddier portion of the intertidal zone, and is common about midway between high and low 
tide marks. The form of body presents many peculiarities, both superficial and in detail, comparable with those which are regarded as characteristic of the Brachyura, furnishing an excellent example of "convergence." . . The abdomen is greatly reduced in size, the length of the carapace scarcely exceeds its breadth, and the habit of clinging to stones is developed to a marked degree.

\section{The Munida rugosa TYPE.}

Characteristic of fairly deep waters (found at depths varying from 10 to 600 fathoms). The general form of body closely resembles that of type A, but obvious specializations for deep-sea life exist.

Thus, within the group Galatheidea, a few species (those of group C) have been driven by stress of competition in the shallower waters to seek shelter in the deeper and more sparsely populated regions of the sea; but the main line of specialization in the group is in the direction A to B -towards adaptation for life higher up the shore. It is the aim of this memoir, by describing details of the structure of the branchial and other organs of the Galatheidea, to show what peculiarities have arisen in connection with the need for special precautions :

(a) For ensuring steadiness of balance when the animal is in progression or at rest within the wave-washed region of the shore;

(b) For guarding against the choking of the branchial cavity and clogging of the branchial organs by the mud of the low shore.

In doing this, an endeavour is made to arrange these details in logical and progressive order, as indicating for the more crab-like members of the group "the base degrees whereby they did ascend."

\section{Modifications which promote EFficiency in Resistance to} WAVE-WASH AND IN PROGRESSION ON THE SHORE.

It is convenient to use the type-species A (Galathea squamifera) as a starting-point from which to trace various lines of specialization within the group, this species being probably among the nearest to the Macrurous ancestor. We find throughout the genus Galathea few specializations of a definitely Anomurous character: the long, rather narrow carapace and powerful abdominal swimming "tail" with broad tail-fan obviously mark the active swimmer. In those members of the group which frequent the higher coast-zones-notably the Porcellanids-and which thus assume the creeping rather than the swimming habit, we note a reduction in importance of the Macrurous characters-a diminution 
in size of the abdomen, accompanied by a broadening of the carapace and strengthening of the ambulatory thoracic appendages. The reduction of the abdomen is well marked in Porcellana platycheles, which, as a general rule, does not swim, but moves from place to place in a crablike sidling fashion. The abdomen, which is habitually carried tucked-up beneath the thorax, is relatively very weak, and narrowly triangular in outline, and the tail-fan, though still present, is reduced in size. The abdomen is rarely unfolded except under special circumstances, as when the animal is upset on to its back. In this case, the abdomen is flapped vigorously, so as to raise the animal in the water and alter the inclination of the body, allowing it to fall back into the natural position, while the chelæ are extended to catch at any means of support to which it may be possible to cling. A similar action of the abdomen has been observed in Cancer and Carcinus individuals, when subjected to similar conditions, but in these two Brachyuran genera the absence of the tailfan renders the flapping less effective; this deficiency, however, is not of much consequence, as their superiority in weight and strength gives Cancer and Carcinus a greater stability than is possessed by Porcellana.

Decapoda which frequent the shore have the carapace much broader and flatter than in Macrura, and this has led to the sharp lateral folding of the carapace, giving protection to the branchial organs ; this broadening is also of importance in connection with the above-mentioned habit of sideway progression, as we generally find the long axis of any body is turned in the direction of habitual movement. This method of advance in another than the forward direction is peculiarly suited to animals endowed with the Decapod Crustacean's type of sense-organs and frequenting obstructed places, and also to those whose walking limbs are spread in the almost radial fashion characteristic of the Porcellanids. The efficient clinging mechanism so afforded is based on the principle which determines the radial spreading of tent-pegs with their ropes, and of the several hooks of a grapnel, and has doubtless been developed in connection with the habit (already marked in Galathea, and most pronounced in Porcellana platycheles) of clinging to the under-surfaces of stones, and thus resisting the force of wave-wash as well as that of enemies. The radial arrangement of the limbs also endows the animal with facility of movement in an oblique, as well as in the directly transverse, direction-a valuable asset to a dweller in the intertidal zone of shifting pebbles.

In connection with the strengthening of the thoracic limbs of Porcellana platycheles, we note in this species the greatest concentration of 
the thoracic nerve-ganglia observed in any of the Galatheidea, the condition almost approaching that which characterizes the Brachyura (see Plate 1, Figs. A, B, C, D, E). The last thoracic leg (appendage XIII), which in the Galatheidea is modified into a slender cleaning-organ, of course does not participate in the clinging action or in locomotion, and it is noticeable that, even in Porcellana platycheles, the ganglion of the 13th segment remains semi-isolated from the central mass formed by the fusion of most of the other thoracic ganglia.

The marked clinging-habit of Porcellana platycheles should be connected not only with the resistance to dislodging forces, but also with the general protective "melting into the background." The body is flattened, and when at rest is pressed closely against the rock-the chelæ are flattened and expanded in the horizontal plane, and are notched so as to fit accurately against the front edge of the carapace-and the whole dorsal body surface is coated with shaggy, grey, insensitive hairs, nearly matching in colour the rock to which the animal clings (see Plate $2, \mathrm{D})$. In this connection we remark also the absence of those transverse ridges of the carapace which are so conspicuous in more active members of the group. These carapace ridges in Galathea are fringed with hairs of a fairly simple, once-pinnate type (Plate 2, A, and Plate 4 , B), whose continual agitation by the motion of the surrounding water probably prevents the settlement of such unwelcome guests as Hydrozoa, Polyzoa, etc., likely to retard the swimmer by increasing the frictionsurface. A sedentary form like Porcellana platycheles has no such interest in avoiding encrustation-and in it we find no trace of ridges or of waving hairs, the shaggy hairs of the dorsal surface being too close and coarse to be easily agitated by movement of the water. Again, the ridges, if present, would inevitably detract from the general protective resemblance to surroundings, and from this standpoint it seems likely that the presence of encrusting organisms may be of positive advantage to the crab. At all events, Spirorbis is quite commonly found attached especially to the chelæ of $P$. platycheles-a position likely to ensure commensalism (Plate 2, D).

\section{Modifications which tend to pRevent Choking BY MUd.}

A Macrurous form such as we suppose the Galatheid ancestor to have been, swimming in the clearer open water, required, and probably possessed, no special devices for protection of the branchial cavity from stoppage: we find in the Lobster, Penæus, etc., a notable absence of such protective devices. Here, the gills are just sufficiently well guarded 
against dangers of friction, etc., by the lateral branchiostegite flap of the carapace, which loosely overhangs the cavity. The case of the Brachyura is quite otherwise. These shore-living Crustacea are constantly exposed to the dangers of life in the wave-washed zone, and protection against one of the greatest of these dangers is ensured by the enclosing of the branchial cavity by the strongly-curved branchiostegite. This leaves only the following apertures : a pair at the posterior end of the carapace, a pair at the bases of the chelæ, a pair near the mouth —and, on each side, a long chink, so narrow as to be practically inconsiderable, between earapace and thoracic leg-bases. The first two pairs of apertures (entrance channels for the breathing current) are well guarded by a straining apparatus formed by a fringe of hairs of very complex structure (Plate $4, \mathrm{G})$, while the aperture on each side of the mouth (an exit channel) can be protected by the folding of the plate-like maxillipedes against the body-wall. The fourth pair of apertures, mere chinks, are curtained by a fringe of hairs bordering the branchiostegite and by the tufts of "coxopoditic setæ."

One might expect to find in Galatheidæ a type of arrangement more or less intermediate between these two extremes-the Macrurous and the Brachyurous-and such is, in fact, revealed. Throughout the group, the closing-in of the branchial cavity is far less complete than in the Brachyura, although a curved and down-bent branchiostegite protects it laterally, and the paired inhalent aperture (posterior, near the bases of appendages XII and XIII) is guarded by a ring of hairs. Coxopoditic tufts also prevent the entrance of mud through the longitudinal crack between branchiostegite and leg-bases-which crack is far wider than in Brachyura, the whole branchial cavity being wide in the vertical rather than in the horizontal plane.

Galathea, an active swimmer, has retained some of the epipodites so characteristic of primitive Macrurous forms like Penæus. In G. squamifera (common around our coasts), there are epipodites, fringed with long and fairly simple hairs, on appendages VIII to XI (Plate 2, B, and Plate 1, F). One important function of the epipodites, as established by M. Bohn ("Des mécanismes respiratoires chez les Crustacés Décapodes," Bull. Sci. Fr. et Belg., XXXVI) is to brush the surfaces of the Arthrobranch gills and sweep them clear of particles. With so efficient a sweeping mechanism, it seems that elaborate precautions against the entrance of mud are unnecessary : we find that in this species the guardian-hairs which fringe the inhalent aperture are of the same fairly simple type as those which occur along the whole of the carapace edge (Plate 7, B). 
This absence of high specialization along this particular line should be correlated with the habitat of the species, which visits the muddiest part of the shore (just below low-tide mark) only for a very short time in spring. The allied species, Galathea strigosa, shows increased complexity of structure of the hairs which guard the inhalent aperture and fringe the branchiostegite. We connect the advance in specialization with the fact, noted by M. Bohn (op. cit.), that " in G. strigosa, considerable movements of the carapace supplement the action of the scaphognathite." This carapace-flapping would doubtless expose any epipodites present on appendages IX to XI to the danger of being bruised and torn-at all events, the epipodites of these segments are wanting. This reduction of sweeping mechanism within doubles the need for a guard at the entrance portals, which need is satisfied by the increased complexity of straining-hairs described above. Thus, in G. strigosa, feebleness of the scaphognathite has induced flapping of the carapace-this being in its turn connected with reduction in the number of epipodites and correlated complexity of straining hairs (see Plate 2, B, and Plate 4, F). It is interesting to note that in this species the epipodite of appendage VIII has alone survived, and this perhaps owing to its position opposite the blunt angle of the branchiostegite, where in all probability friction is not great.

Galathea intermedia, like G. strigosa, has suffered reduction in the number of its epipodites (though we are as yet unable to guess at the biological significance of this reduction); here, only epipodites VIII and IX remain, and here again correlated specialization of the straininghairs is observed (Plate 4, E).

Two deep-water species of Galatheidea-G. nexa (to 70 fathoms) and Munida subrugosa (to 600 fathoms)-while resembling G. squamifera in their possession of the full number of epipodites (series VIII to XI), yet afford a parallel with the case of $G$. strigosa and $G$. intermedia in the relatively complex structure of the straining-hairs. This apparent anomaly seems to point to a need for special precaution against choking of the branchial passage in these two deep-water species; this is one item of a lengthy list of peculiarities which characterize the branchial apparatus of deep-sea members of widely dissociated groups (compare the peculiarities of the branchial organs of the Lepetidæ among Prosobranch Gasteropods, etc. etc.).

A striking feature of such shore-living types as Porcellana is the complete loss of the epipodites of appendages VIII to XI. This reduction should perhaps be correlated with the marked development of the 
clinging habit and the radial working of the legs, which entail movements likely to endanger organs occupying the position of epipodites. We should probably connect with this habit of spreading the legs radially (a habit which prevails throughout the Galatheidea, though it is most marked in Porcellana) the peculiarities of the general gill-formula of the group, which is characterized by the absence of podobranchs and importance of the pleurobranchs. Some of the leg movements involved would seem to be a source of danger to gills in the position of podobranchs (near the outer edge of the branchial chamber), exposing them to a risk of friction against one another and against the edge of the branchiostegite. Reduction of the organs exposed to this danger is accompanied by increased importance of the gills of the two inner series (arthrobranchs and pleurobranchs). (See Plate 1, F and G.)

In connection with the ascent of the shore by Porcellanidæ, the alteration in shape of the branchial cavity is noticeable, the shape of the cavity being practically of a type intermediate between those found in the swimming Galathea and the established (unrelated) shore-form, Cancer.

Porcellana platycheles, a sluggish species inhabiting the muddiest part of the mud-zone, shows a marked degree of specialization of the hairs which guard the inhalent aperture. These hairs, as well as those of the coxopoditic tufts, are of a much-branched and twice-pinnate type, and exactly resemble those which, in members of the Brachyura, constitute so effective a strainer, being totally dissimilar to the corresponding structures in Galathea (any species). (Plate 4, G.)

It is remarkable that $P$. longicornis, unlike platycheles, has none of this complicated structure: all the hairs near openings of the branchial cavity are alike of the simple type characteristic of Galathea squamifera (Plate 4, B).

It is necessary to bear in mind the difference in habitat of the two species, $P$. platycheles being a typical mud-dweller, whilst longicornis frequents such shores as those of Guernsey, where igneous rocks weather into reefs separated by steep gullies, swept perfectly clear of mud by the tidal currents.

With specializations which tend to promote efficiency of the breathing current we must class a peculiar growth of hairs found on the basal joint of the third maxillipede of all species so far examined. These hairs are short and strong, furnished with short, jagged saw-teeth, and are matted together to form a kind of felt-work across the gap between the maxillipedes of the two sides. This acts as a forward extension of the floor of the branchial cavity, and seems to guard against the entrance of water 
from below, which might meet and check the outgoing current (see Plate 4 and Text Figure 1).

Various members of the group show an interesting series of devices ensuring steadiness of the breathing current-such devices being particularly necessary in animals with the enclosed type of branchial cavity. Prof. Pearson, in his Cancer Memoir (L.M.B.C.), has pointed out the existence in that part of the carapace which floors the branchial cavity of a ridge, which by its presence helps to maintain a steady current of water past the gills. Specializations of an apparently somewhat similar function are visible in certain of the Galatheidea. The branchial cavity of Galathea and of Munida is long and narrow, with a slight spiral twist,

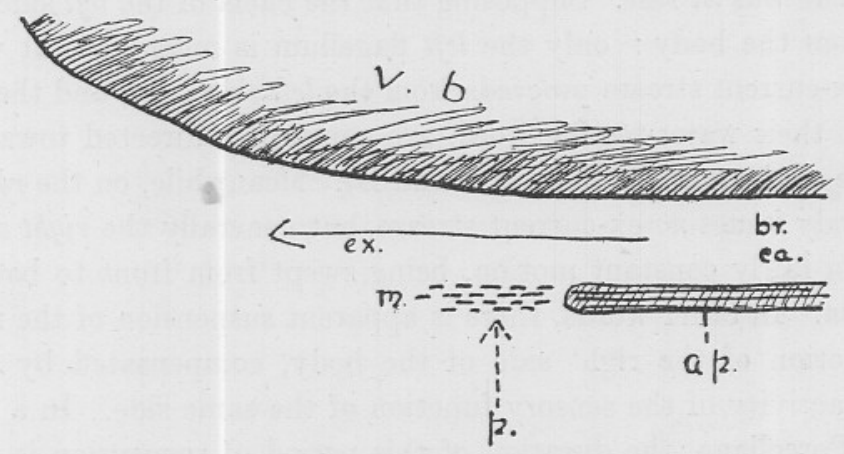

FIG. 1.-Diagram-Longitudinal section through the front end of the body of one of the Galatheidea.

v.b. = ventral body-wall.

ap. = branchiostegite of one side.

br.ca. = branchial cavity of that side.

ex. $=$ direction of ex-current stream.

p. = line of a theoretical in-current.

m. = position of matted hairs on the maxillipede bases, which prevent the entrance of the current $p$.

and is floored (unlike those of Brachyura) by the body-wall itself: we trace in this floor the line of a definite, though not prominent, longitudinal ridge external to a groove along which the main body of the breathing current appears to flow (Plate 3, A, i and ii).

Porcellana has a corresponding specialization more nearly of the Cancer type : the branchial cavity is partially floored (i.e. towards its front end) by a special portion of the edge of the branchiostegite, which is peculiarly twisted to produce a ridge doubtless similar in function to the rather more definite ridge of Cancer (Plate 3, B, and Plate $1, \mathrm{G}$ ).

Porcellana shows a remarkable respiratory habit-that of temporary suspension of the breathing activities on alternate sides of the body. 
The flagellum of one of the maxillipedes (probably of the 2nd) is obviously of use in strengthening and accelerating the ex-current stream, and its motion or stillness forms a good guide to the progress of the breathing activities on either side of the body, in addition to the indication furnished by the motion of particles in the water. It was noticed that both $P$. longicornis and $P$. platycheles, when at rest, almost invariably hold the chela of one side $(\alpha)$ further away from the body than its fellow $(\beta)$ : subsequent observation, many times confirmed, revealed the fact that only from the exhalent aperture of the $\alpha$ side did an excurrent stream proceed : apparently no respiratory stream was passing. through the branchial cavity of the $\beta$ side, and certainly the flagellum of that side was at rest. Supposing that the chela of the left side is held away from the body: only the left flagellum is meanwhile at work, a strong ex-current stream proceeds from the left side only, and the antennules, at their water-testing work, are constantly directed towards the right side of the animal (Plate 2, C and D). Meanwhile, on the right side of the body issues no ex-current stream, but generally the right antenna is kept in fairly constant motion, being swept from front to back, and vice versa. In other words, there is apparent suspension of the respiratory function of the right side of the body, compensated by the redoubled activity of the sensory function of the same side. In a normal captive Porcellana, the duration of this period of suspension is usually about half an hour; at the end of that time the animal becomes restless, "fidgets," and ends by reversing the functions of the two sides of the body, after a brief period of irregular movement of first one flagellum, then the other, and occasionally even of both at once. It must be noticed that in Porcellana there is no reversal of the current such as M. Bohn observes (C.R. Ac. Sci., CXXV, 1897, p. 441, "Sur le renversement du courant respiratoire chez les Décapodes ") in Carcinus, etc., and which may serve to rest the muscles of the scaphognathite or to cleanse the branchial cavity. Probably this resting of the muscles is at least as well ensured by the alternate working of the organs of the two sides. M. Bohn remarks that, in animals which have the reversal habit, the number of reversals within a given time may be increased by placing the animal in a toxic solution such as extract of Red Seaweed. Similar experiments performed on Porcellana produced no reversal of the current, but had the effect of causing the alternations in function of the two sides to become rapid and irregular. Galathea exhibits no such alternation, and on placing it in Red Seaweed extract there was detected distinct reversal of the respiratory stream, although the backward current produced was but 
feeble and irregular. The result of the experiments performed on Porcellana is surely to show that any recuperative purpose effected by the reversal of the respiratory stream in the Decapods for which such reversal has been proved is fulfilled in Porcellana by the alternate resting and working of the two sides.

Throughout the Galatheid group we note a praiseworthy striving after cleanliness on the part of its members, which must of course be referred to the habitat of these animals. Apart from the absolute necessity for keeping a clear channel through the branchial cavity, it is of distinct advantage to prevent mud particles from collecting among the hairs of the coxopoditic tufts and near the openings of the branchial cavity itself, and it is clearly the function of the curiously modified thirteenth (last thoracic) appendage to clean and brush these hairs, as well as the back of the carapace. Galathea and Munida especially have need of precaution against the settling of foreign particles in the transverse grooves of the carapace. The ultimate segment of the thirteenth appendage in Galathea, Munida, and Porcellana, bears hairs which by their structure are peculiarly well fitted for this work of cleaning out chinks and crannies (Plate 4, K), each hair being bent into a kind of sickle-shaped hook, fringed on its inner side with short, pointed teeth, and doubtless constituting a most effective scraper. In one species of Porcellana ( $P$. platycheles, see Plate $\nearrow, \mathrm{K}, \mathrm{ii})$, these hairs appear to have suffered degeneration from some unexplained cause (perhaps in connection with the absence of carapace ridges), growing less strongly curved and with blunt teeth. It is noticeable that members of the genus Porcellana (without epipodites) frequently thrust this appendage XIII inside the branchial cavity itself, doubtless to clean it-a course of proceeding which Galathea (furnished with epipodites) apparently does not follow.

The antennules (water-testing organs) and the antennæ (which are still important tactile organs in the Galatheidæ) must, if they are to retain their sensory function, be kept scrupulously clean, and their cleansing, which frequently takes place, is a process to delight the observer. These appendages are bent sharply downward, then the endopodites of the third maxillipedes are unfolded, and antennules and antennæ are drawn slowly upwards in such a manner as to be thoroughly well combed by the long hairs of these palps, which hairs have the form of strong double-edged saws or combs (Plate 4, I, i). These endopodites of the third maxillipedes, by the way, exhibit an interesting series of specializations throughout the group. Their main functions are $(a)$ to gather

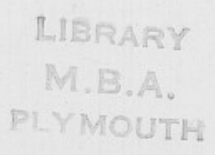


in small particles of food to the mouth by a sweeping movement; (b) to comb the hairs of antennæ and antennules; and $(c)$ to guard, when folded, the exit channels of the branchial cavity. In Galathea and Munida, the joints of the endopodite are long and thin, and the whole maxillipede approaches in form the type of the primitive Arthropod appendage, save that the endopodite is slightly flattened, and can, when folded, form a fairly plate-like structure. $P$. platycheles shows greater specialization of the endopodite, the joints being very much flattened and broadened, although the span of the limb when straightened is considerable. $P$. longicornis is in this respect almost intermediate between the two types (Plate 6, A, B). All these species have specialized hairs of two kinds on the ultimate and penultimate segments of the endopodite. These are-(a) sweeping hairs (Plate 4, C), very long and slender, bearing two regular rows of fine branches; and (b) combing hairs (Plate 4, I, i), not so long as the former, but stouter, and bearing two rows of very stiff points like the teeth of a double comb.

Comparison with the third maxillipede of Cancer and allied Brachyura is instructive. In Cancer, the broadening and flattening of the proximal portion of the endopodite and the reduction of its distal joints have proceeded far (see Plate 3, D, E, F). The function of the endopodite here is perhaps exclusively to protect the exit channel, and it is converted into an organ primarily plate-like and protective, and destitute of sweeping hairs. In connection with the life high up the shore, antennæ and antennules are reduced in size and importance (experiments prove the former to be practically insensitive to touch), so that this double reduction renders the combing of antennæ and antennules by the hairs of VIII impracticable. The combing hairs, having lost their function, are obviously degenerate : though they retain their two rows of lateral branches, these branches are so much thickened as to be almost fused in rows, and quite disqualified as combing teeth. The fact that Algal growth has been found attached to the antennæ of practically every specimen of $C$ ancer pagurus examined appears to prove conclusively the absence of combing device and sensitivity. Carcinus (a more active Brachyuran than Cancer, and one proved by experiment to have greater power of antennal perception), has the third maxillipede just long enough to clean the antenna tip, and it is noticed that in members of this genus the combing hairs have persisted without degeneration - also Algal growth is less commonly present on the antenna, and never present near the tip. On the other hand, $P$. platycheles presents, in this matter of the combing hairs, a condition markedly analogous with that of Cancer. This must be connected with the general 
crab-like habit and sluggish nature of the species (compare the settlement of Spirorbis, etc., on the carapace and chelæ).

In this last instance, then, $P$. platycheles exhibits a type of specialization markedly analogous with that of the true crabs, and the species once more asserts its right to be placed among the upper branches of our tree of Galatheid ascent.

\section{EXPLANATION OF PLATES.}

\section{Plate 1.}

A.-E : Thoracic nervous systems of Decapod Crustaceans.

A. Of Astacus fluviatilis (after Huxley).

B. Of Galathea squamifera

C. Of Munida rugosa members of the Galatheidea.

D. Of Porcellana platycheles

E. Of Cancer pagurus.
Gn. $1 . \quad=$ supra-œsophageal mass.
C. $\propto . \quad=$ circum-œsophageal ring.
S. $\propto . \quad=$ sub-œsophageal ganglion.
S. $n . \quad=$ gap for sternal artery.
Gn. 4, 5-8. =last 5 thoracic ganglia.
Gn. 8. =ganglion of segment XIII.
Vn. $\quad=$ ventral nerve-mass.

$\mathrm{F}$ and $\mathrm{G}$. Branchial cavity of right side, showing bases of thoracic legs.
A. Of $G$. squamifera.
B. Of $P$. platycheles.

Pl. X to XIII=Pleurobranchia.

Ep. VIII to XI=Epipodites.

\section{Plate 2.}

A. Side view of carapace of Galathea strigosa.

Ep. VIII=epipodite of the 3rd maxillipede (usually turned into the branchial cavity).

B. An epipodite of $G$. squamifera, showing sweeping hairs.

Ms:= muscle.

D. P. platycheles, dorsal view. The flagellum of the left side is at work. (N.B.-In this specimen, the chela of the right side is the larger. The illustration by no means does justice to the general shagginess of the species.) 
C. Enlarged view (diagrammatic) of a portion of the above.
a. =antennules.
m. =plate-like endopodite of VIII.
fl. =flagellum at work.
ex. $=$ ex-current stream.
S. =Spirorbis tube on chela.

Plate 3.

A. Side view of branchial cavity of $G$. squamifera, gills removed (diagrammatic).

c. = cut edge of body-wall, etc.

In. =inhalent aperture.

Ex. =exhalent aperture.

Gr. = position of groove.

r. $=$ line of a not prominent ridge.

$\mathrm{A}$ ii, $\mathrm{B}$ i and $\mathrm{ii}$, and $\mathrm{C} \mathrm{i}=$ diagrams of various branchial cavities in T.S.

A ii. Of $G$. squamifera.

B. Of $P$. platycheles (i, near front end; ii, further back).

Ci. Of $C$. pagurus.

$\mathrm{B}$ iii. = Branchiostegite of $P$. platycheles, inner surface.

$\mathrm{C}$ ii. = Branchial cavity of Cancer exposed.

r. = ridge.

br. =branchiostegite.

c. = cut edge of carapace.

D. $=3 \mathrm{rd}$ maxillipede of $G$. squamifera (right side).

$\begin{array}{lll}\mathrm{E} .=, & , & \text { "P. platycheles } \\ \mathrm{F} .=, & \quad, & \text { "C.pagurus }\end{array}$

en. $=$ endopodite.

ex.=exopodite.

G. =Antenna of C. pagurus, with Algal growth.

Plate 4.

Drawings of single hairs (much enlarged).

A. Simple hair, e.g. "shaggy hairs" of P. platycheles.

B. Once-pinnate hair, on carapace ridges of Galathea, also fringing the branchiostegite in G. squamifera.

C. In-sweeping hair, on last two joints of endopodite of 3rd maxillipede in Galatheidea.

D. Epipodite hair.

E. Filter hair, fringing branchiostegite, etc., in G. intermedia, G. nexa, and Munida subrugosa. 
F. Strigosa hair, fringing branchiostegite, etc., in G. strigosa.

G. Tree-like filter hairs, fringing branchial apertures of $P$. platycheles and Cancer, etc.

i. Cluster, with collected mud.

ii. Tip of one hair, more highly magnified.

H. Matted hairs, inner side of basal joint of 3rd maxillipede in Galatheidea.

I i. Combing hair, last two joints of VIII in Galathea, Munida, P. longicornis, and Carcinus monas.

ii. Degenerate combing hair, $P$. platycheles and $C$. pagurus.

Ki. Sickle hair, ultimate joint of XIII in Galatheidea (except P. platycheles).

ii. Degenerate sickle hair ( $P$. platycheles). 
K. Zimmermann.

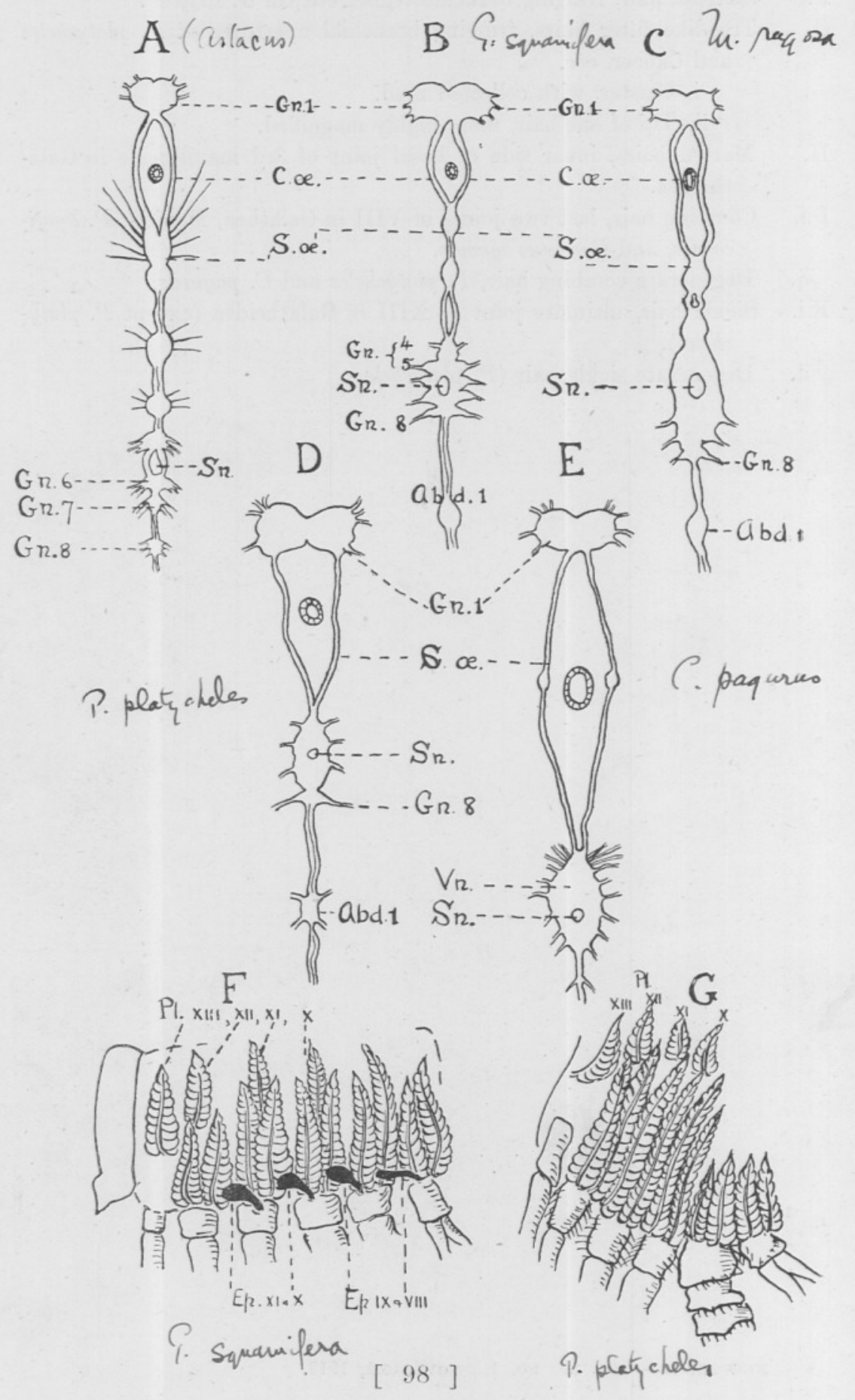




\section{A}
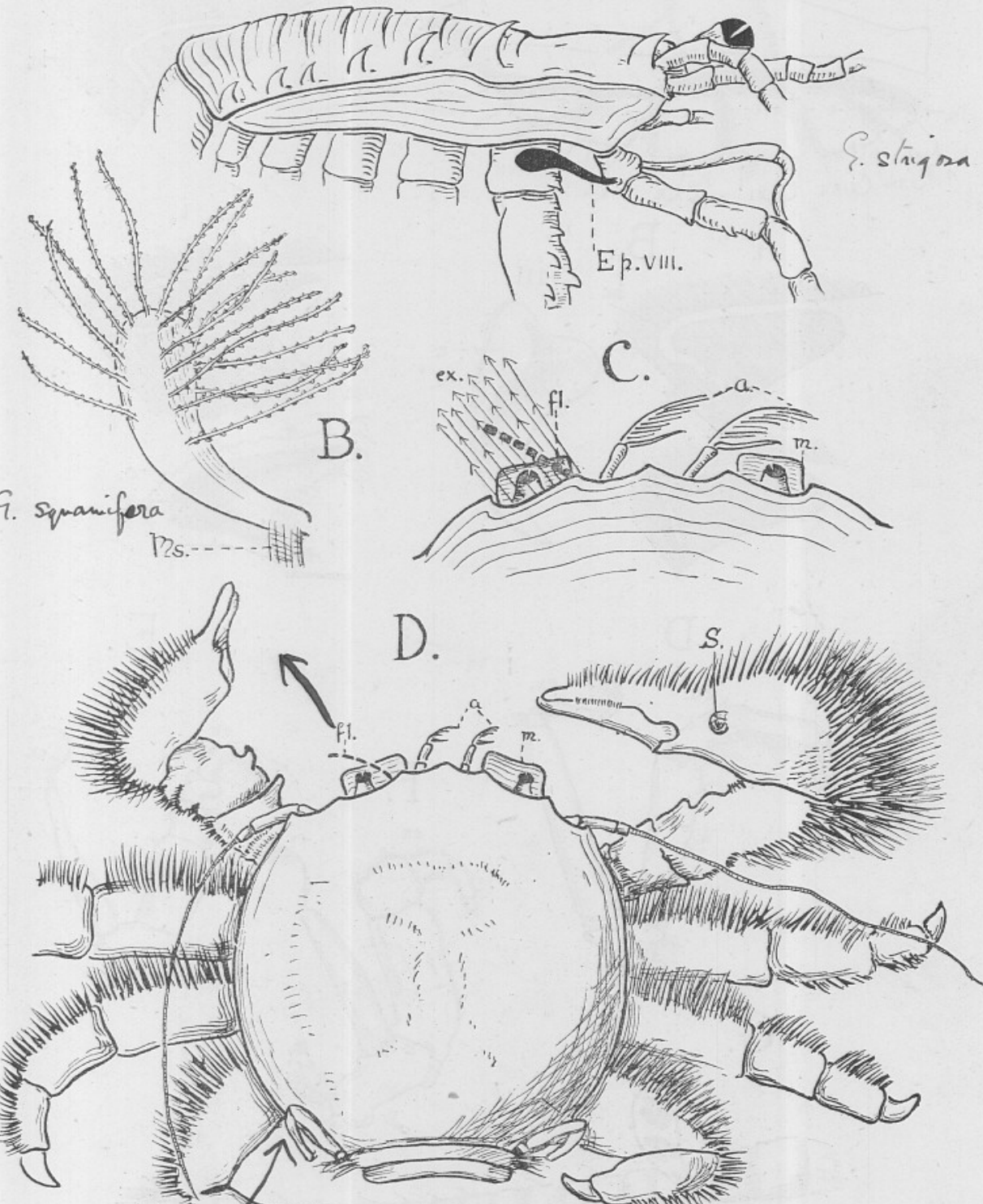

D.

$$
\text { a }
$$



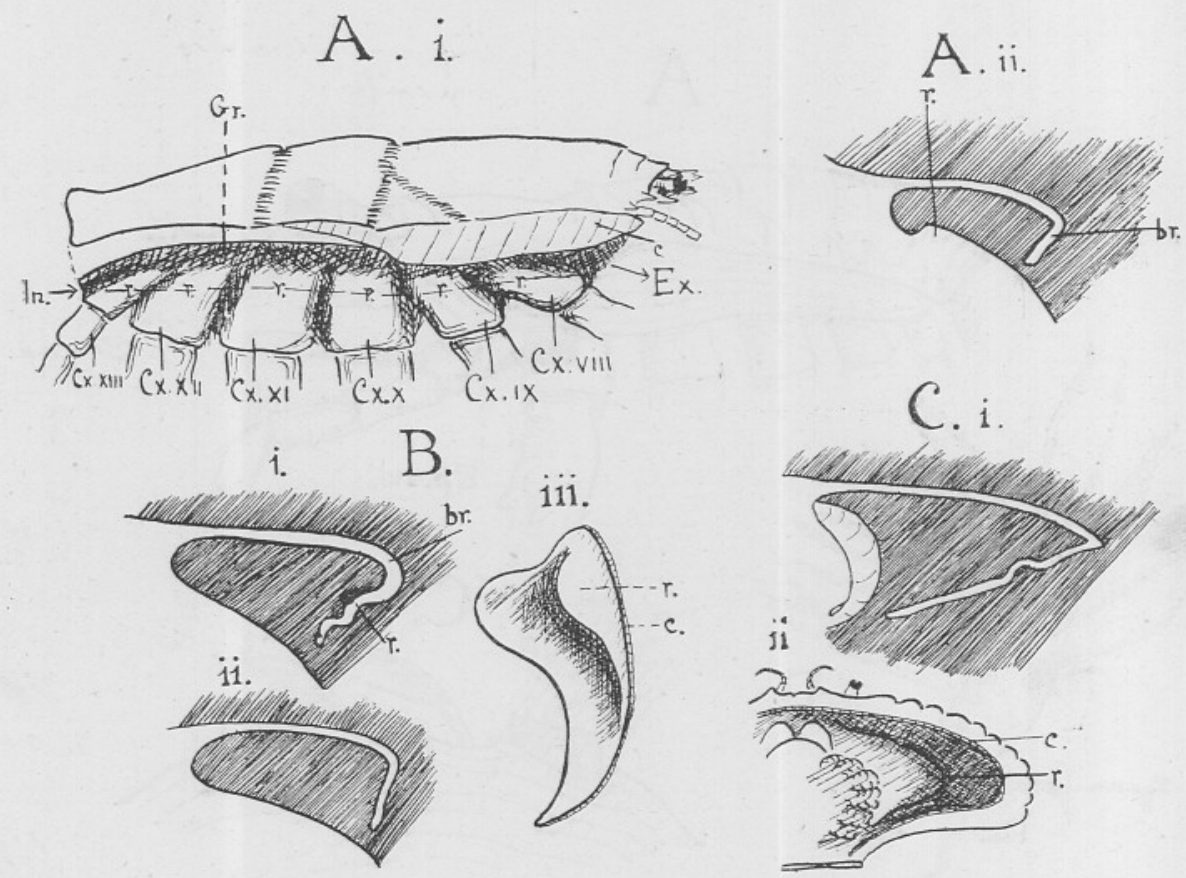

D.

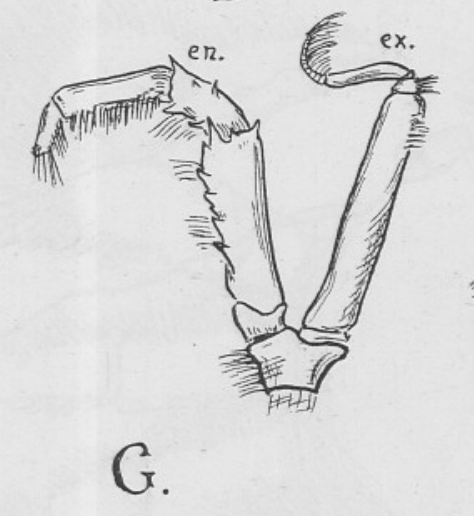

E.

(10)

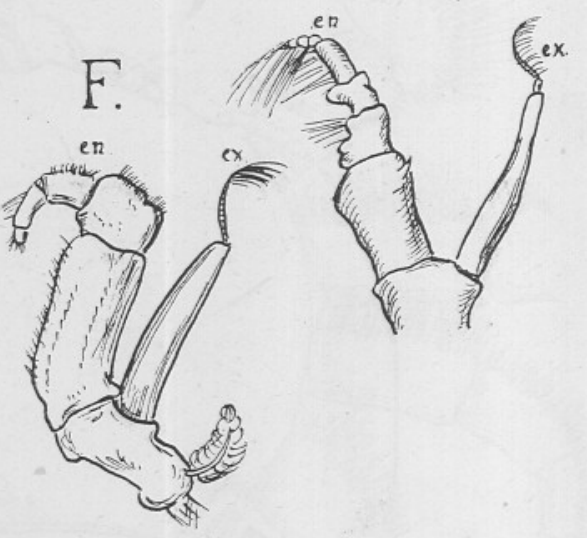


Habit and Habitat in Galatheidea.

Plate IV

K. Zimmermann.

B. P. Ponicarmic (stäiniong)

A.

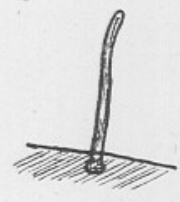

c.

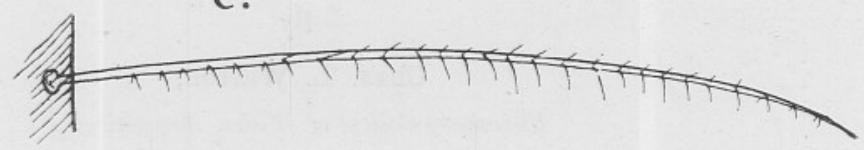

D.
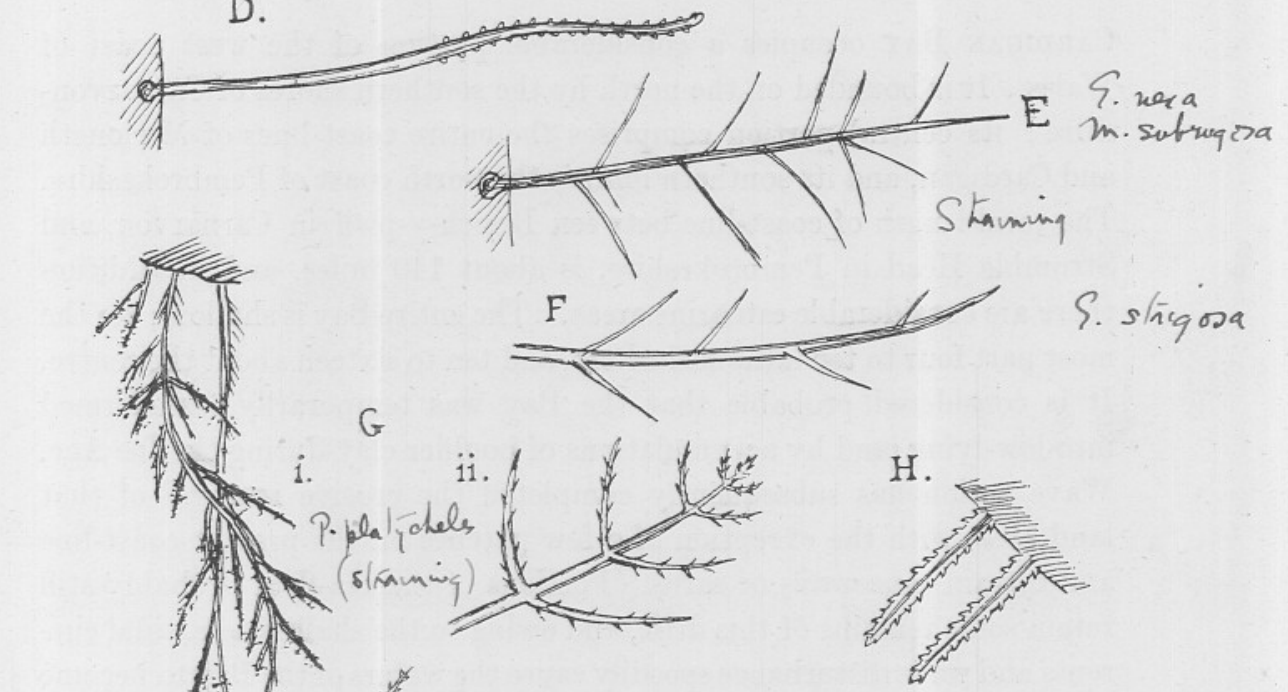

K.

Saveep inp $(x / 11)$

i. Salatteas.

P.Conquanis ii.

P. platycteles

[ 101 ] 